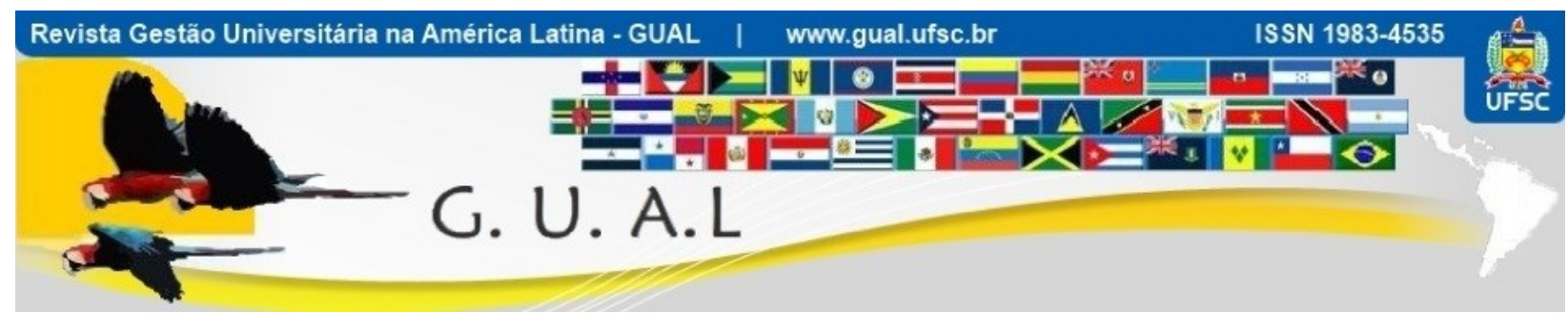

DOI: http://dx.doi.org/10.5007/1983-4535.2013v6n3p111

\title{
A ESTRUTURA DO ENSINO SUPERIOR NO BRASIL
}

\section{THE STRUCTURE OF HIGHER EDUCATION IN BRAZIL}

Leonardo Roth, Mestrando

Universidade de Caxias do Sul - UCS

1roth@ucs.br

André Mauro Santos de Espíndola, Mestrando Universidade de Caxias do Sul - UCS espindola.andre@gmail.com

Vivian Oliveira Santos, Mestranda

Universidade de Caxias do Sul - UCS

oliveirasantos.vivian@gmail.com

Eric Charles Henri Dorion, Doutor Universidade de Caxias do Sul - UCS edorion@ucs.br

Ana Cristina Fachinelli, Doutora Universidade de Caxias do Sul - UCS afachinelli@ucs.br

Eliana Andréa Severo, Doutoranda Universidade de Caxias do Sul - UCS elianasevero2@,hotmail.com

Recebido em 22/abril/2013

Aprovado em 10/julho/2013

Sistema de Avaliação: Double Blind Review 


\title{
RESUMO
}

O ensino superior no Brasil passou recentemente por uma reformulação legal e estrutural. Em um contexto onde o país, no cenário mundial destaca-se como um mercado em desenvolvimento que começa a atrair a atenção de grandes empresas multinacionais onde, a qualificação da mão de obra é fundamental, dentro de uma visão de inteligência competitiva. Este trabalho busca, através de uma revisão da literatura, compreender a estrutura do ensino superior brasileiro, descrevendo as questões legais, estruturais e específicas. Foi possível verificar que as mudanças ocorridas a partir da Constituição de 1988, a publicação na nova Lei de Diretrizes e Bases da Educação - LDB em 1999, o baixo nível de investimento público no ensino superior e a demanda de mercado abriram a possibilidade de um maior investimento privado na educação superior. Dentre as instituições privadas, as comunitárias tem assumido um papel fundamental ao assumir a responsabilidade de instância intermediária entre o conhecimento produzido e transmitido, suprir a demanda do mercado, formando mão de obra qualifica para atender os problemas sociais e econômicos pertinentes da comunidade.

Palavras-chave: Educação. Estrutura do ensino superior. Universidades.

\begin{abstract}
Higher education in Brazil has recently undergone a makeover legal and structural. In a context where the country stands on the world stage as a developing market that is beginning to attract the attention of large multinational companies where the skills of the workforce is crucial within a vision of competitive intelligence. This paper seeks, through a literature review, understand the structure of higher education in Brazil, describing the legal, structural and specific. It was possible to verify that the changes that occurred since the Constitution of 1988, the publication of the new Law of Guidelines and Bases of Education - LDB in 1999, the low level of public investment in higher education and market demand have opened the possibility of a greater private investment in higher education. Among private institutions, the EU has played a key role in taking responsibility instance intermediate between the knowledge produced and transmitted, meet market demand, forming qualified manpower to meet the social and economic problems relevant community.
\end{abstract}

Keywords: Education. Structure of higher education. Universities. 


\section{INTRODUÇÃO}

Vivemos uma época de grandes transformações culturais, sociais e econômicas. Transformações que tiveram início no século passado onde segundo Druker (1995) foi o século de maior número de transformações sociais.

Nonaka (1994), afirma que a economia de hoje tem base no conhecimento, e que o sucesso das empresas passa pela capacidade de adquirir novos conhecimentos e disseminá-lo por toda organização.

Para Druker (1993), a sociedade que vivemos se diferencia das anteriores pelo papel fundamental que o conhecimento desempenha nela. $O$ autor dá tanta importância ao conhecimento que trata o mesmo como o recurso mais significativo atualmente e singular na nova sociedade.

Druker (1995, p.35), afirma que nesta sociedade existe um novo tipo de trabalhador o "trabalhador do conhecimento", que este profissional só terá acesso a empregos e posição formal através da educação formal.

Stewart (2000, p.19), corrobora com a visão de Druker e denomina a era que vivemos com "era da informação" e que nesta era a grande riqueza são o conhecimento e a comunicação, e estes começam a assumir precedência ao recursos naturais e ao trabalho físico.

Segundo Porter (1998), no atual modelo de competição global a base da competição se voltou mais para criação e para assimilação do conhecimento, e neste contexto o papel danação cresceu.

Ao observamos as visões e as falas destes autores fica muito claro o papel do conhecimento na sociedade moderna. Mas o conhecimento depende muito das estruturas educacionais adotadas por cada país. Conhecer e estudar o sistema de educação de um país passa ser um papel fundamental para o planejamento estratégico das organizações e das nações. Segundo Porter (1998), a prosperidade de uma nação deve ser criada e não herdada, nesta linha o autor afirma que a capacidade competir de uma nação nasce da sua capacidade de inovar e modernizar-se.

A inovação e a modernização de uma nação passa diretamente pelos sues sistema de educação e principalmente pelo sistema de educação superior. Neste contexto o presente trabalho busca descrever o sistema de educação superior brasileiro, tentando apresentar o cenário nacional após a constituição de 1998 e a LDB de 1996. A principal questão que o 
artigo pretende responder é: “Quais as características da educação superior no Brasil e quais as possibilidades de crescimento deste setor?”.

\section{REVISÃO DA LITERATURA}

\subsection{AS UNIVERSIDADES}

As universidades, segundo Ulmann (2000), não existiam antes do século XII ou XIII. $\mathrm{O}$ autor destaca que essas instituições eram como agremiação de professores e alunos, cosmopolita, com significado social e político, homologadas pelos papas e reis. Para ser reconhecida como universidade, Ulmann (2000) afirma que bastava um curso ou uma faculdade isolada que congregasse uma corporação de alunos e professores.

Em suas abordagens, Ulmann separa as universidades em escolas pré-universitárias e medievais. A primeira está subdividida em: a) a Escola de Buda; b) a Escola de Confúcio; c) a Escola de Pitágoras; d) a Academia de Platão; e) o Liceu de Aristóteles; e, f) os sofistas o jardim e o Pórtico. Já as universidades medievais, localizadas em Alexandria, em Constantinopla e no Cairo, são: a) o Mouseîon; b) Didascália; c) Constantinopla; e, d) AlAzhar em Cairo.

As universidades, como base de criação do seu próprio interesse na busca do conhecimento, corre risco constante pelas excitações políticas religiosas, patrióticas e de desenvolvimento (MINOGUE, 1981). Nesse contexto o autor salienta que as instituições devem se separar dos acontecimentos que as rodeiam, sendo um local de desprendimento e ponderação sobre as ideias.

Assim, Dias Sobrinho (2000), destaca que a universidade é uma instituição moderna alicerçada em duas bases do iluminismo: o Estado e a razão. O autor destaca ainda que uma universidade moderna assenta-se em duas vertentes, uma no discurso filosófico de Fichte e Schleiermacher e outra de Humboldt. Em seus estudos, Maamari et al., (2006), corrobora com o autor ao afirmar que o conhecimento de Filosofia ofertado nas universidades é fundamental para a formação de todas as profissões.

Dias Sobrinho (2000), destaca ainda que o modelo alemão de universidade, datado de 1810, enfatiza a autonomia especulativa do saber. Já o modelo francês dá ênfase ao caráter instrumental das universidades como provedora de mão de obra. Outro modelo abordado, o humboldtiano, se baseia no modelo teleológico / especulativo e o modelo napoleônico no caráter instrumental. 
Com isso, se observa que independente do campo do saber, a função de uma universidade é formar quadros superiores com capacidade de reflexão crítica e social, propiciando respostas a sociedade através do fornecimento de profissionais para o país (MINOGUE, 1981; MAAMARI, et al., 2006; DIAS SOBRINHO, 2000).

\subsection{ENSINO SUPERIOR NO BRASIL}

Desde sua colonização, por muito tempo o Brasil referenciou um sistema de ensino superior localizado nas metrópoles importantes de sua época, com foco elitista e para a orientação profissional e priorizando mais o ensino do que a pesquisa. Martins (2009), aborda que a partir de 1950 um novo modelo de ensino superior se instalou no Brasil. Esse modelo foi representativo para a reforma universitária de 1968, momento que, o desenvolvimento de uma rede universitária no País era limitada (ORTIZ, 2002; MARTINS, 2009).

Segundo Vannucchi (2011), entre os séculos XVI e XVII, por intermédio da atuação dos jesuítas, franciscanos, carmelitas, beneditinos e capuchinos deu-se início a história da educação brasileira. Estes criaram a partir do trabalho evangelizador, escolas confessionais, estas, nem públicas, nem privadas, ou seja, o que predominava era a doutrina aos colonizados pelos colonizadores.

No Brasil, após a constituição de 1998, existem dois segmentos de instituições de ensino superior as públicas e as privadas. Conforme a Constituição de 1988, através de uma separação político administrativa e de ensino, delegando aos Municípios, ao Distrito Federal, aos Estados e a União as obrigatoriedades em seus diferentes níveis (BRASIL, 2011).

No Art. 211 a Constituição estabelece que: $\S 2^{\circ}$ )Os Municípios atuarão prioritariamente no ensino fundamental e na educação infantil; $\S 3^{\circ}$ ) Os Estados e o Distrito Federal atuarão prioritariamente no ensino fundamental e médio.

Explicitamente, a Constituição não destaca de qual nível da esfera pública (Municípios, Estados ou União) é a responsabilidade do ensino superior. A constituição em seu Art. 207 descreve que as universidades têm autonomia didático-cientifica, administrativa e de gestão financeira e patrimonial e devem obedecer ao princípio de indissociabilidade entre ensino, pesquisa e extensão (BRASIL, 2011).

A LDB (BRASIL, 2007), em seu artigo 52 define as universidades como "instituições pluridisciplinares de formação dos quadros profissionais em nível superior, de pesquisa e extensão e de domínio e cultivo do saber humano". No mesmo artigo, a LDB traz a caracterização das universidades por: 
a) produção intelectual institucionalizada mediante o estudo sistemático dos temas e problemas mais relevantes, tanto do ponto de vista científico e cultural, quanto regional e nacional; b) um terço do corpo docente, pelo menos, com titulação acadêmica de mestrado ou doutorado; c) um terço do corpo docente em regime de tempo integral.

A LDB (BRASIL, 2007), em seu Art. 53 trata da autonomia constitucional assegurada às universidades, e define que no exercício de sua autonomia as universidades possuem as seguintes atribuições: a) criar, organizar e extinguir, em sua sede, cursos e programas de educação superior previstos nesta Lei, obedecendo às normas gerais da União e, quando for o caso, do respectivo sistema de ensino; b) fixar os currículos dos seus cursos e programas, observadas as diretrizes gerais pertinentes; c) estabelecer planos, programas e projetos de pesquisa científica, produção artística e atividades de extensão; d) fixar o número de vagas de acordo com a capacidade institucional e as exigências do seu meio; e) elaborar e reformar os seus estatutos e regimentos em consonância com as normas gerais atinentes; f) conferir graus, diplomas e outros títulos; g) firmar contratos, acordos e convênios; h) aprovar e executar planos, programas e projetos de investimentos referentes a obras, serviços e aquisições em geral, bem como administrar rendimentos conforme dispositivos institucionais; i) administrar os rendimentos e deles dispor na forma prevista no ato de constituição, nas leis e nos respectivos estatutos; j) receber subvenções, doações, heranças, legados e cooperação financeira resultante de convênios com entidades públicas e privadas.

Essa autonomia da legislação brasileira não especifica se o ensino é público ou privado. Conforme o Art. 44 da LDB (BRASIL, 2007), o ensino superior se subdivide em cursos sequenciais, de graduação e pós-graduação onde:

I - cursos sequenciais por campo de saber, de diferentes níveis de abrangência,
abertos a candidatos que atendam aos requisitos estabelecidos pelas instituições de
ensino, desde que tenham concluído o ensino médio ou equivalente; II - de
graduação, abertos a candidatos que tenham concluído o ensino médio ou
equivalente e tenham sido classificados em processo seletivo; III - de pós-
graduação, compreendendo programas de mestrado e doutorado, cursos de
especialização, aperfeiçoamento e outros, abertos a candidatos diplomados em
cursos de graduação e que atendam às exigências das instituições de ensino; IV - de
extensão, abertos a candidatos que atendam aos requisitos estabelecidos em cada
caso pelas instituições de ensino.

Nesse nivelamento do ensino superior deve-se ressaltar que a legislação não especifica em nível de graduação, as licenciaturas e os cursos de tecnologia e na pós-graduação os MBA. Essa não especificação não minimiza ou exclui esses cursos, pois os mesmos estão enquadrados na grande área da titulação. 
Evidentemente que essa autonomia presente na legislação brasileira somada a não especificação da responsabilidade publica ou privada sobre o ensino superior proporcionou o surgimento e a instalação de diversas Instituições de Ensino Superior (IES) em nosso País.

O quadro 1 apresenta um histórico da educação superior no Brasil a partir do ano de 1995 até o ano de 1998, este foi dividido em instituições públicas ou privadas.

Tabela 1 Número de IES - Brasil - 1995 / 1998

\begin{tabular}{ccc} 
Ano & Públicas & Privadas \\
\hline 1995 & 210 & 684 \\
1996 & 211 & 711 \\
1997 & 211 & 689 \\
1998 & 209 & 764 \\
Total & 841 & 2848 \\
\hline
\end{tabular}

Fonte: Elaborada pelos autores com base no Censo do Ensino Superior INEP (2012)

Ao observar os dados apresentados na tabela 1 é possível verificar que o número de instituições públicas permaneceu quase inalterado no período em quanto as privadas apresentaram um crescimento de 11,69\% com relação ao ano de 1995.

A LBD (1996) em seu artigo 20 enquadra as IES privadas em quatro categorias assim definidas:

I - particulares em sentido estrito, assim entendido as que são instituídas e mantidas por uma ou mais pessoas físicas ou jurídicas de direito privado que não apresentem as características dos incisos abaixo;

II - comunitárias, assim entendidas as que são instituídas por grupos de pessoas físicas ou por uma ou mais pessoas jurídicas, inclusive cooperativas de professores e alunos que incluam na sua entidade mantenedora representantes da comunidade;

III - confessionais, assim entendidas as que são instituídas por grupos de pessoas físicas ou por uma ou mais pessoas jurídicas que atendem a orientação confessional e ideologia específica e ao disposto no inciso anterior;

IV - filantrópicas, na forma da lei. (Lei 8742/1993).

Com esta categorização das IES pela LDB o cenário nacional começa a mudar a partir de 1999, o que podemos verificar na tabela 2.

A tabela 2 traz uma nova visão sobre o número de IES no Brasil após a nova LDB, é possível verificar um crescimento no número de instituições públicas na ordem de 47,91\% em relação ao ano de 1999. As instituições privadas também apresentaram um crescimento significativo de $295,62 \%$ no mesmo período. Mas ao compararmos com a tabela 1 podemos verificar o INEP traz dados também das IES comunitárias e confessionais, e que neste período o número de IES comunitárias e confessionais teve uma redução de 23,48\%. Outra informação importante que podemos tirar ao comparar os dados da tabela $1 \mathrm{com}$ a tabela 2 é que entre 1998 de 2011 o número total de IES no Brasil cresceu 443,48\%. 
Tabela 2 Número de IES - Brasil - 1999 / 2011

\begin{tabular}{cccc} 
Ano & Públicas & Privadas & $\begin{array}{c}\text { Comunitárias } \\
\text { Confessionais }\end{array}$ \\
\hline 1999 & 192 & 526 & 379 \\
2000 & 176 & 698 & 306 \\
2001 & 183 & 903 & 305 \\
2002 & 195 & 1.125 & 317 \\
2003 & 207 & 1.302 & 350 \\
2004 & 224 & 1.401 & 388 \\
2005 & 231 & 430 & 414 \\
2006 & 248 & 1.583 & 439 \\
2007 & 249 & 1.594 & 438 \\
2008 & 236 & 1.579 & 437 \\
2009 & 245 & 1.779 & 290 \\
2010 & 278 & 2100 & -- \\
2011 & 284 & 2081 & -- \\
Total & 2948 & 17101 & 406 \\
\hline
\end{tabular}

Fonte: Elaborada pelos autores com base no Censo do Ensino Superior INEP (2012)

As IES tem como função, além do ensino de graduação, o ensino de pós-graduação stricto sensu, segundo a CAPES (2012), a oferta predomina-se nas IES públicas e está informação é possível de ser verificada no gráfico 1 que traz as séries históricas dos percentuais de cursos pós-graduação stricto sensu no Brasil entre 1998 e 2011.

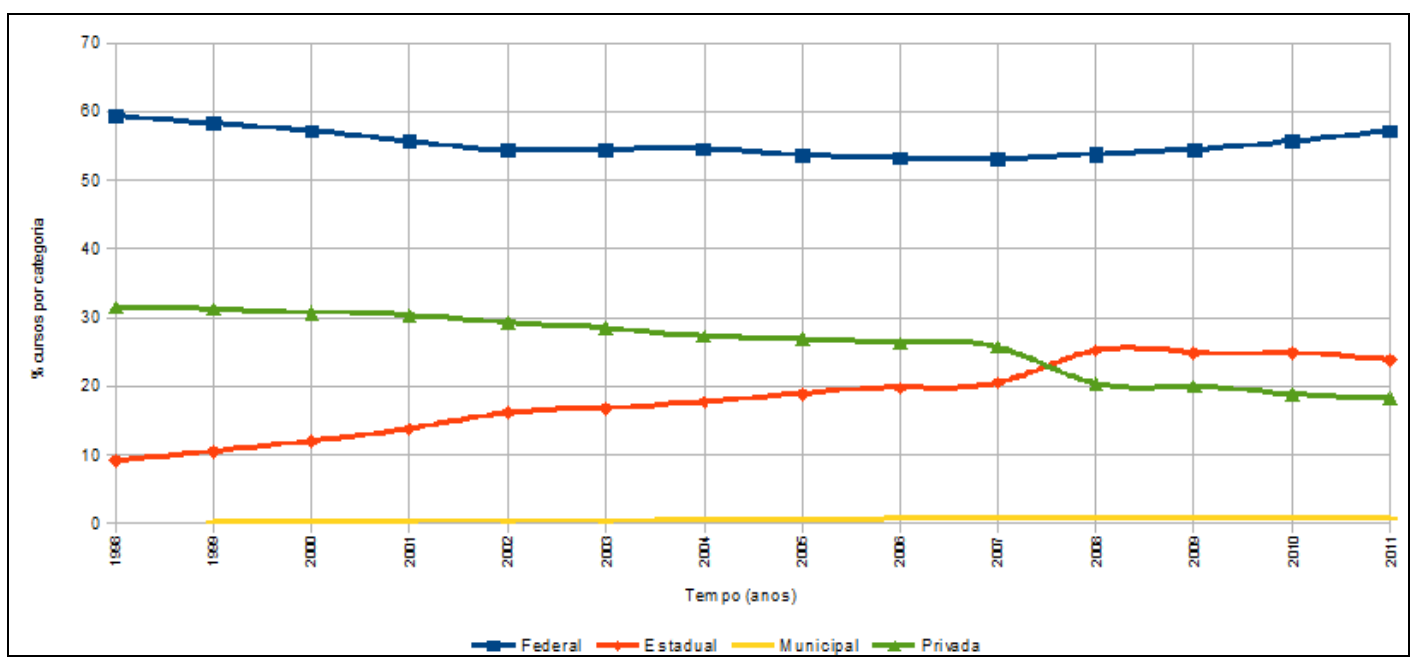

Gráfico 1 Cursos de pós-graduação - Brasil - 1999 / 2011

Fonte: Elaborado pelos autores com base nos dados estatísticos da CAPES (2012)

Destaca-se que se considerou apenas a oferta dos programas de Doutorado, Mestrado e Mestrado Profissional disponíveis no portal da CAPES (CAPES, 2012). Observase também, que as IES Estaduais apresentaram crescimento até 2008 enquanto as instituições Federais, a partir do ano de 2007, reiniciaram uma pequena elevação na oferta de cursos que 
se mantinha relativamente estável. Ressalta-se porém que, nesse período houve um crescimento de $40.67 \%$ na oferta de cursos recomendados de acordo com os dados georeferenciais da CAPES (CAPES, 2012).

\section{AS INSTITUIÇÕES DE ENSINO SUPERIOR NO BRASIL}

O ensino superior no Brasil está subdividido em instituições públicas e privadas que oferecem diferentes cursos nas mais diversas áreas do saber. As IES Públicas estão subdivididas em universidades, faculdades e institutos tecnológicos. Já as privadas, segregamse em particulares, confessionais, filantrópicas, comunitárias, faculdades isoladas e centros universitários.

A LDB (BRASIL, 2007) em seu Art. 19 classifica as instituições ensino em seus diferentes níveis como: “a) públicas, assim entendidas, as criadas ou incorporadas, mantidas e administradas pelo Pode Público. b) privadas, assim entendidas as mantidas e administradas por pessoas físicas ou jurídicas de direito privado".

Com base nos dados históricos entre os anos de 1995 a 2011, disponibilizados pelo Instituto Nacional de Estudos e Pesquisas Educacionais Anísio Teixeira - INEP, vinculado ao Ministério da Educação, o Brasil, no ano de 2011 possuía 2.365 IES espalhadas por todas as unidades da federação (INEP, 2012). Destas, 2.081 instituições são privadas que correspondem $88 \%$ das IES do País conforme demonstrado no gráfico 2.

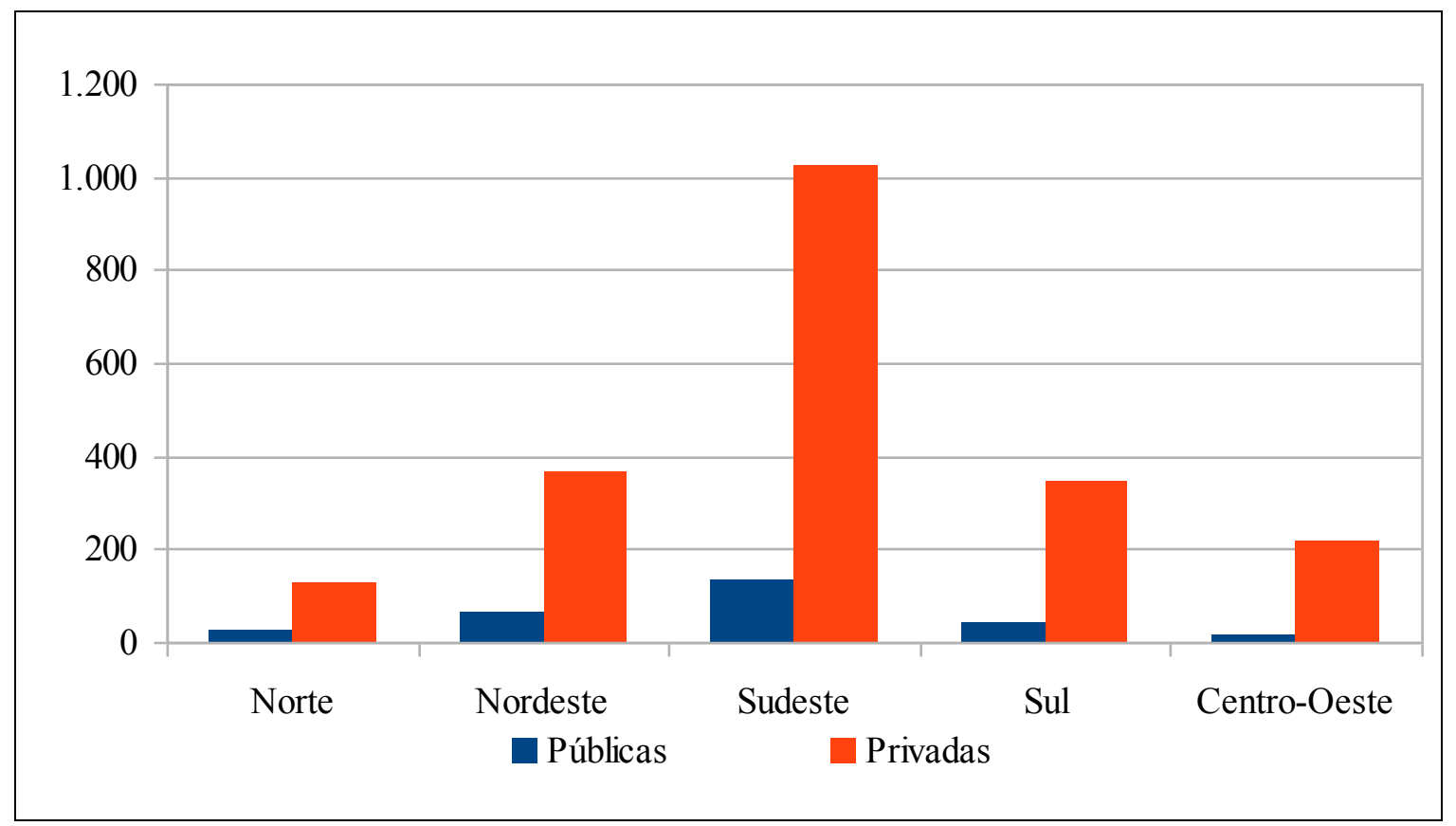

Gráfico 2: Distribuição geográfica da IES - Brasil - 2012

Fonte: Elaborado pelos autores com base nos dados do Censo do Ensino Superior 2011 (INEP, 2012). 
Observa-se que as instituições concentram-se na região sudeste e existe uma distribuição simétrica das de instituições nas outras regiões em torno da região sudeste. Também é possível observar que existe uma predominância de IES privadas.

Considerando essa subdivisão, apresentamos a tabela 3 com a distribuição territorial por unidade federativa das IES publicada no Censo de 2011 (INEP, 2012), demonstrando assim, a real localização das instituições no Brasil considerando-se também a distribuição das IES no interior e na capital de cada estado.

Tabela 3 Distribuição das IES por estado - Brasil - 2012

\begin{tabular}{|c|c|c|c|c|c|c|}
\hline Estado & $\begin{array}{c}\text { Total } \\
\text { Capital }\end{array}$ & $\begin{array}{c}\text { Total } \\
\text { Interior }\end{array}$ & $\begin{array}{l}\text { Pública } \\
\text { Capital }\end{array}$ & $\begin{array}{l}\text { Pública } \\
\text { Interior }\end{array}$ & $\begin{array}{l}\text { Privada } \\
\text { Capital }\end{array}$ & $\begin{array}{l}\text { Privada } \\
\text { Interior }\end{array}$ \\
\hline Rondônia & 14 & 18 & 2 & - & 12 & 18 \\
\hline Acre & 10 & 1 & 2 & - & 8 & 1 \\
\hline Amazonas & 19 & - & 3 & - & 16 & - \\
\hline Roraima & 7 & - & 3 & - & 4 & - \\
\hline Pará & 19 & 14 & 4 & 1 & 15 & 13 \\
\hline Amapá & 15 & 1 & 3 & - & 12 & 1 \\
\hline Tocantins & 10 & 24 & 3 & 6 & 7 & 18 \\
\hline Maranhão & 16 & 14 & 3 & - & 13 & 14 \\
\hline Piauí & 26 & 11 & 3 & - & 23 & 11 \\
\hline Ceará & 33 & 20 & 3 & 3 & 30 & 17 \\
\hline Rio Grande do Norte & 15 & 10 & 3 & 2 & 12 & 8 \\
\hline Paraíba & 22 & 16 & 2 & 2 & 20 & 14 \\
\hline Pernambuco & 34 & 60 & 4 & 24 & 30 & 36 \\
\hline Alagoas & 16 & 10 & 3 & 1 & 13 & 9 \\
\hline Sergipe & 12 & 2 & 1 & 1 & 11 & 1 \\
\hline Bahia & 46 & 69 & 4 & 4 & 42 & 65 \\
\hline Minas Gerais & 53 & 302 & 6 & 22 & 47 & 280 \\
\hline Espírito Santo & 26 & 62 & 3 & 1 & 23 & 61 \\
\hline Rio de Janeiro & 75 & 62 & 11 & 12 & 64 & 50 \\
\hline São Paulo & 141 & 436 & 8 & 71 & 133 & 365 \\
\hline Paraná & 54 & 131 & 5 & 16 & 49 & 115 \\
\hline Santa Catarina & 14 & 79 & 3 & 8 & 11 & 71 \\
\hline Rio Grande do Sul & 29 & 82 & 3 & 7 & 26 & 75 \\
\hline Mato Grosso do Sul & 11 & 26 & 2 & 2 & 9 & 24 \\
\hline Mato Grosso & 15 & 42 & 2 & 1 & 13 & 41 \\
\hline Goiás & 28 & 54 & 3 & 5 & 25 & 49 \\
\hline Distrito Federal & 59 & - & 3 & - & 56 & - \\
\hline Total & 819 & 1546 & 95 & 189 & 724 & 1357 \\
\hline
\end{tabular}

Fonte: Elaborada pelos autores com base no Censo 2011 INEP (2012)

Destaca-se, pela tabela que o volume de IES em nosso País fora das capitais é substancial, correspondendo a $65,35 \%$ do total das instituições.

Com base nos dados é possível observar que o ensino superior é descentralizado territorialmente no País onde, e pelo não crescimento significativo das instituições públicas, as IES privadas conquistam um espaço que as públicas não conseguem se apossar. 


\section{UNIVERSIDADES COMUNITÁRIAS, FILANTRÓPICAS E CONFESSIONAIS}

As universidades comunitárias, ao lado das entidades do Terceiro Setor, são entidades privadas de utilidade pública. Sem fins lucrativos, essas IES, cujo patrimônio deve ser disponibilizado apenas a sua finalidade, formam as diversas organizações sem vínculos diretos com o Primeiro Setor (Público, o Estado) e o Segundo Setor (Privado, o Mercado). Em síntese, são entidades formalmente constituídas como aquelas sem fins lucrativos, que apesar de não integrarem o aparelho governamental, prestam serviços que são deveres do Estado, com autonomia gerencial e, em contrapartida, recebem isenções e incentivos fiscais.

Outhwaite (1996) destaca que comunitário é aquilo que é comum à comunidade, o que é coletivo, o que é de todos os membros da comunidade. Distingue-se do estatal e do privado por não pertencer ao Estado nem a grupos com interesses comerciais.

As IES comunitárias, estão presentes em 12 Estados da Federação correspondendo a uma população de 142.425.301 segundo o censo demográfico de 2010 (IBGE, 2012). Essas instituições, num total de 62 (ABRUC, 2012) estão instaladas, além do Distrito Federal,, nos seguintes Estados: Paraná, Pernambuco, Bahia, Minas Gerais, Rio de Janeiro, São Paulo, Paraná, Santa Catarina, Rio Grande do Sul, Mato Grosso e Goiás.

A ABRUC (2012) descreve-as como instituições sem fins lucrativos que desenvolvem essencialmente ações educacionais. As atividades de ensino, pesquisa e extensão com excelência, acrescenta-se a vocação social, a presença expressiva nas áreas da saúde. Destaca ainda, em seu Estatuto os critérios de aceite, ou seja, as características de uma IES comunitária:

I - estar legitimamente constituída no país, sob a forma de fundação de direito privado, de associação ou de sociedade civil; II - pertencer o seu patrimônio a uma comunidade, sem dependência do poder público, de famílias, empresas ou outros grupos com interesses econômicos; III - aplicar integramente no território nacional suas rendas, recursos de qualquer espécie e eventual resultado operacional, na manutenção e desenvolvimento de seus objetivos institucionais; IV - não distribuir resultados, dividendos, bonificações, participações ou parcelas de seu patrimônio, sob nenhuma forma ou pretexto; V - não privilegiar seus integrantes, associados, membros, participantes, instituidores ou filiados, na prestação de seus serviços; VI ter como instância máxima uma Assembleia ou Conselho com a participação de representantes da comunidade na qual está inserida; VII - ter o controle da administração da gestão financeira de todos os seus recursos através de organismos com participação da comunidade à qual está vinculada e, no caso das fundações, também através do Ministério Público; VIII - não remunerar seus dirigentes, integrantes, membros, participantes, instituidores ou filiados, com salários, vantagens, dividendos, bonificações ou parcelas de seu patrimônio, quando no desempenho de suas funções estatutárias, nada impedindo, entretanto, que eles recebam por seu trabalho, no exercício de funções docentes ou administrativas, nas instituições mantidas; IX - destinar, em caso de dissolução ou extinção da entidade, o patrimônio remanescente a uma entidade pública com finalidades similares; X - 
ser reconhecida como entidade de Utilidade Pública Federal, Estadual ou Municipal; XI - manter sempre presente seu objetivo social, considerada a natureza e o interesse público de suas atividades; XII - zelar para que o seu patrimônio e suas atividades estejam vinculadas diretamente aos seus objetivos e funções;

Essas instituições, segundo a ACAFE (2012), são de interesse público, criadas pela sociedade civil e pelo poder público, tornando-se reconhecidas e importantes para o desenvolvimento regional. Cita ainda outras características:

Sem fins lucrativos, com gestão democrática e participativa, constituem autênticas instituições públicas não-estatais em favor da inclusão social e do desenvolvimento do País e reinvestem todos os resultados na própria atividade educacional. $\mathrm{O}$ envolvimento direto da comunidade acontece através dos conselhos e na própria gestão, que é democrática.

Segundo Vannucchi (2011) as instituições comunitárias surgem da ausência das universidades estatais e da incapacidade das IES confessionais de instalarem-se fora dos grandes centros. Pela mobilização da sociedade civil, lideranças locais e regionais, o autor afirma que, inicia-se aí, um movimento de criação de cursos superiores isolados para resolução de carências regionais específicas.

Passos (2008), pelo viés confessional, destaca em seus estudos que o comunitarismo não se restringe a um setor ou departamento, mas sim em todas as ações acadêmicas da universidade. $\mathrm{O}$ autor destaca também que essa dimensão comunitária, instituída pelas universidades confessionais, estão presentes na essência de uma universidade como sendo um espaço autônomo de produção e transmissão de conhecimento para a sociedade.

Ainda assim, o Art. 213 da Constituição brasileira (BRASIL, 2011) destaca que os recursos públicos poderão ser investidos em escolas comunitárias, confessionais ou filantrópicas que:

I - comprovem finalidade não-lucrativa e apliquem seus excedentes financeiros em educação; II - assegurem a destinação de seu patrimônio a outra escola comunitária, filantrópica ou confessional, ou ao Poder Público, no caso de encerramento de suas atividades. $\S 1^{\circ}$ - Os recursos de que trata este artigo poderão ser destinados a bolsas de estudo para o ensino fundamental e médio, na forma da lei, para os que demonstrarem insuficiência de recursos, quando houver falta de vagas e cursos regulares da rede pública na localidade da residência do educando, ficando o Poder Público obrigado a investir prioritariamente na expansão de sua rede na localidade. $\S$ $2^{\circ}$ - As atividades universitárias de pesquisa e extensão poderão receber apoio financeiro do Poder Público.

Por sua relevância essas IES, se comparadas as instituições públicas e privadas, desempenham papel importante no sistema de ensino superior.

Mesmo com a retração no crescimento das IES confessionais e comunitárias demonstradas anteriormente na tabela 2 , a segregação das instituições em públicas, privadas e 
confessionais e comunitárias é fundamental para o real entendimento da importância desse modelo de IES para o desenvolvimento do ensino superior no Brasil.

\section{MÉTODO}

Este estudo teve como objetivo descrever a estrutura do ensino superior no Brasil avaliando o número de IES existentes assim como a sua classificação e distribuição no território nacional. Para tanto foi desenvolvido um levantamento exploratório, pois através dele se familiarizou com as características legais e estruturais do ensino superior para aprimorar ideias ou a descoberta de possibilidades ou intuições sobre estudo e, descritivo no momento que buscou descrever características do ensino superior no Brasil (GIL, 2008).

A pesquisa teve uma abordagem qualitativa buscando analisar a legislação e os dados referentes ao ensino superior brasileiro para obter mais informações e definir o problema com mais precisão (MALHOTRA, 2011).

O procedimento adotado na elaboração deste trabalho foi o de documentação indireta, que segundo Lakatos (2001) busca em dados ou informações coletados por outras informações relevantes para a pesquisa. A primeira foi o de revisão da literatura existente para melhor fundamentação dos conceitos e da legislação que rege a educação superior no Brasil.

$\mathrm{Na}$ segunda etapa foi feito um levantamento de dados referentes ao ensino superior no Brasil na busca da descrição da distribuição das IES. Por fim este estudo pode ser classificado como sendo longitudinal, pois buscou rastrear quais as mudanças históricas do ensino superior no Brasil ao longo do tempo (MALHOTRA, 2011).

\section{CONSIDERAÇÕES FINAIS}

O ensino superior no é muito jovem se comparado com as origens do ensino superior que datam do século XII e XIII. Legalmente, a atual estrutura do ensino superior brasileiro passa por transformações devido as recentes políticas governamentais. Durante o levantamento de informações para este trabalho, foi possível verificar que por muito tempo a maioria das IES eram públicas.

Após a Constituição de 1988 e a nova LDB de 1999 é possível verificar um crescimento de $295,62 \%$ no número de IES privadas e, no mesmo período, as instituições públicas apresentaram um crescimento de 47,91\% tendo como base o ano de 1999. Esse crescimento tem duas origens: a primeira está relacionada com a lacuna deixada pelas IES públicas que não acompanharam o crescimento da demanda e a segunda, a partir das políticas 
adotadas na nova legislação que possibilitaram um maior investimento por parte do setor privado.

A lacuna deixada pelas IES públicas é devido ao baixo nível de investimento no ensino superior e pela localização destas instituições principalmente em grandes centros, agrada pelas dimensões continentais de nosso país. Esse espaço deixado pelas públicas, propiciou, a criação de outro modelo de ensino privado, o confessional/comunitário.

Essa segregação entre públicas, privadas e confessionais/comunitárias, propiciou, além do aumento de vagas ofertadas uma melhor distribuição das instituições no território nacional. O modelo confessional/comunitário tenta, como instância intermediária entre o conhecimento produzido e transmitido, suprir a demanda do mercado, formando mão de obra qualifica para atender os problemas sociais e econômicos pertinentes da comunidade.

Assim, destacamos a importância de se conhecer melhor o sistema de ensino superior brasileiro. A sua importância está diretamente relacionada com o momento econômico que o país passa e, pelo planejamento estratégico que deve ser elaborado.

O Brasil, é um dos países, que no cenário mundial, destaca-se como um mercado em desenvolvimento que começa a atrair a atenção de grandes empresas multinacionais onde, a qualificação da mão de obra é fundamental, dentro de uma visão de inteligência competitiva.

A compreensão da estrutura do ensino superior, a identificação de suas deficiências e de suas qualidades e de forma antecipada, pode se tornar uma fonte de vantagem competitiva para as empresas que pretendem investir em nosso país referendando a necessidade de novos estudos sobre os modelos de ensino superior brasileiro, comparando-os com os modelos externos e com os incentivos governamentais para envio de brasileiros ao exterior para qualificação.

\section{REFERÊNCIAS}

ABRUC-Associação Brasileira das Universidades Comunitárias. Disponível em: $<$ http://www.abruc.org.br/. Acesso em 16 out. 2012.

ABRUC Comunica. Edição Especial no 5. Brasília, março, 2011.Disponível em: < http://www.abruc.org.br/sites/500/516/00001961.pdf> Acesso em 14 nov. 2012.

ACAFE - Associação Catarinense das Fundações Educacionais. Disponível em $:<$ http://www.universidadecomunitaria.com.br> Acesso em 11 nov 2012. 
BITTAR, M. Universidade Comunitária: uma identidade em construção. 1999, 252 p. Tese de Doutorado. Universidade Federal de São Carlos, 1999. Disponível em:

$<\mathrm{http}$ ://www.comunitarias.org.br/docs/teses/mariluce_bittar.pdf $>$ Acesso em 13 nov. 2012.

BRASIL. Constituição da República Federativa do Brasil: de 5 de outubro de 1988. 34.ed. São Paulo: Atlas; 2011.

BRASIL. LDB: Lei de diretrizes e bases da educação : Lei 9.394/96 e legislação correlata. 2.ed. Rio de Janeiro: Roma Victor, 2007.

BRASIL. Câmara. Deputados. Projeto de Lei no 7639/2010. Dispõe sobre a definição, qualificação, prerrogativas e finalidades das Instituições Comunitárias de Educação Superior ICES, disciplina o Termo de Parceria e dá outras providências. Brasília, 2012. Disponível em: $<$ http://www.camara.gov.br/proposicoesWeb/fichadetramitacao?idProposicao=483544 $>$ Acesso em 15 nov. 2012.

CAPES. Coordenação de Aperfeiçoamento de Pessoal de Nível Superior. Disponível em $:<$ http://geocapes.capes.gov.br/geocapesds/\#app $=$ c501\&da7a-selectedIndex $=0 \& 5317$ selectedIndex $=0 \& \mathrm{dbcb}$-selectedIndex $=0>$ Acesso em 04 nov. 2012.

COMUNG. Consórcio das Universidades Comunitárias Gaúchas. Disponível em $<$ http://www.comung.org.br/comung > Acesso em 11 nov. 2012.

DIAS, S. J.; RISTOFF, D. I. Universidade desconstruída: avaliação institucional e resistência. Florianópolis: Insular, 2000.

DIAS S., J.; BALZN, N., C. Avaliação institucional: teoria e experiências . São Paulo: Cortez, 1995.

DRUCKER, P., F. Administração de organizações sem fins lucrativos: princípios e práticas. 2.ed. São Paulo: Pioneira, 1994.

DRUCKER, P., F. Administrando em tempos de grandes mudanças.São Paulo: Pioneira, 1995.

DRUCKER, P., F. Sociedade pós-capitalista. São Paulo, SP: Thomson, c1993.

FERNANDES, R.,-C.. Privado porém público: o terceiro setor na América Latina. 2.ed. Rio de Janeiro: Relume Dumará, 1994.

GIL, A. C. Métodos e técnicas de pesquisa social. 6. ed. São Paulo: Atlas, 2008.

IBGE. Instituto Brasileiro de Geografia e Estatística. Censo Demográfico 2010. Disponível em: < http://www.ibge.gov.br/home/> Acesso em 11 nov 2012.

INEP. Instituto Nacional de Estudos e Pesquisas Educacionais Anísio Teixeira - Censo da Educação Superior 2011. Disponível em: < http://portal.inep.gov.br/superior-censosuperiorsinopse> Acesso em: 16 out. 2012. 
LAKATOS, E. M.; MARCONI, M. A. Metodologia do trabalho científico: procedimentos básicos, pesquisa bibliográfica, projeto e relatório, publicações e trabalhos científicos. 6.ed. rev. e ampl. São Paulo: Atlas, 2001. 219 p.

MAAMARI, A., M.; BAIRROS, A., T., C., de; WEBER, J., F. Filosofia na universidade. Ijuí, RS: UNIJUÍ, 2006.

MALHOTRA, N. K. Pesquisa de marketing: foco na decisão. 3.ed. São Paulo: Pearson, 2011. xx, $491 \mathrm{p}$.

MARTINS, C. B., A reforma universitária de 1968 e a abertura para o ensino superior privado no Brasil. Educ. Soc., Campinas, vol. 30, n. 106, p. 15-35, jan./abr. 200915. Disponível em: <http://www.scielo.br/pdf/es/v30n106/v30n106a02> Acesso em 02 nov. 2012.

MINOGUE, K., R. O conceito de universidade. Brasília: Ed. UnB, 1981.

NONAKA, I. (1994). “'A dynamic theory of organizational knowledge creation', Organization Science, Vol. 5 No. 1, pp. 14-37.

ORTIZ, R. As ciências sociais e a cultura. Tempo Social; Rev. Sociol. USP, São Paulo, 14 (1):1932, maio de 2002.

OUTHWAITE, W.; BOTTOMORE, T. B.; LESSA, R., SANTOS, W., G., dos. Dicionário do pensamento social do século XX. Rio de Janeiro: J. Zahar, 1996.

PASSOS, J. D. Carisma e ação da universidade comunitária: experiência da PUC-SP. São Paulo: EDUC, 2008.

PORTER, M., E.; MONTGOMERY, C., A. Estratégia: a busca da vantagem competitiva. Rio de Janeiro: Campus, 1998. 501 p.

SCHMIDT, J., P. Instituições comunitárias: instituições públicas não-estatais. Santa Cruz do Sul, RS: EDUNISC, 2009.

STEWART, T., A. Capital intelectual: a nova vantagem competitiva das empresas. 10.ed. Rio de Janeiro: Campus, 2000. xxi, 237 p. ISBN 85-352-0247-1.

SZAZI, E. (Org). Terceiro setor - temas polêmicos 1. São Paulo, Petrópolis, 2004.

ULLMANN, R., A. A universidade medieval. 2. ed. Porto Alegre: EDIPUCRS, 2000.

VANNUCCHI, A. A universidade comunitária: o que é, como se faz. 3.ed. São Paulo: Loyola, 2011.

VOLTOLINI, R. (Org.) Terceiro Setor: planejametno e gestão. São Paulo: Senac, 2004. 